Western North American Naturalist 69(3), (C) 2009, pp. 382-387

\title{
MARSILEA MOLLIS (MARSILEACEAE) SPOROCARPS AND ASSOCIATED INSECT PARASITISM IN SOUTHERN ARIZONA
}

\author{
Kathryn Mauz ${ }^{1,2}$ and John R. Reeder ${ }^{1,3}$
}

\begin{abstract}
We report observations on reproductive phenology, fecundity, and sporocarp morphology for a population of the semiaquatic fern Marsilea mollis B.L. Rob. \& Fernald in southern Arizona and document the parasitic relationships of 2 insects collected with the plants. The recently described weevil Notiodes sporocarpicus O'Brien (Coleoptera: Curculionidae) utilizes the fern's sporocarp as a brood chamber, only the second documented instance of this form of parasitism in the United States. The wasp Lyrcus maculatus (Gahan) (Hymenoptera: Pteromalidae) is a parasitoid of the weevil in this system.
\end{abstract}

Key words: Marsilea mollis, Notiodes sporocarpicus, Curculionidae, Lyrcus maculatus, Pteromalidae, parasitism.

Marsilea mollis B.L. Rob. \& Fernald is a semiaquatic fern distributed principally throughout the Mexican highlands and found sporadically in central and southern Arizona and southwestern Texas (Johnson 1986, Johnson 1993). These perennial, rhizomatous plants form dense colonies around seasonal ponds. Plants belonging to Marsileaceae produce their sporangia in stalked, indurate, seed-like structures called sporocarps, which in M. mollis are borne singly on a stalk (pedicel) arising at or near the base of the associated leaf's petiole (Johnson 1986). Inside, spore-bearing sorimembranous, saclike structures containing numerous micro- (male) and fewer mega(female) spores-occupy the lower two-thirds of the sporocarp cavity (e.g., Puri and Garg 1953: fig. 43). Sporocarps are produced only by plants in the terrestrial phase (Johnson 1986).

Incidence of parasitism in Marsilea sporocarps has been published in 2 instances. In a terrestrial population of M. minuta L. in northwestern India, larvae of the weevil genus Echinocnemus reportedly infested $90 \%$ of sporocarps. In that system, the weevil's eggs were laid on the soil, and larvae had subsequently entered the developing sporocarps (Loyal and Kumar 1977). Elsewhere, weevils identified as Endalus celatus Burke (=Notiodes celatus Burke) were found associated with $M$. mucronata A. Braun (=M. vestita Hook. \& Grev.; see Johnson 1993) and were also reared from sporocarps of these plants (Board and Burke 1971). At the same time, 2 wasp parasitoids-Bracon punctatus (Mues.) (Braconidae) and Trimeromicrus sp. (=Lyrcus sp., Pteromalidae)—were found associated with the weevil larvae in these sporocarps (Board and Burke 1971.) Although the latter was reported only at the rank of genus, the wasp specimen collected by V.V. Board that is curated in the collection of the U.S. National Museum is $L$. maculatus (Gahan) (G.A.P. Gibson personal communication).

In the present study, we charted sporocarp production by M. mollis at 1 location in 2 growing seasons (2006-2007) and documented sporocarp dimensions in the 2 collections. We observed parasitism by the recently described species of semiaquatic weevil Notiodes sporocarpicus O'Brien and by the wasp parasitoid Lyrcus maculatus collected incidentally with the plant specimens. We compare our observations to the insect-Marsilea relationships described by Board and Burke (1971), particularly the timing of sporocarp production and the locations of holes on the sporocarps resulting from oviposition and emergence.

\section{Study AreA}

The study population of Marsilea mollis encircled an unnamed earthen stock pond at $1553 \mathrm{~m}$ elevation in the San Rafael Valley, Santa Cruz County, southern Arizona, on the

${ }^{1}$ University of Arizona Herbarium, Box 210036, University of Arizona, Tucson, AZ 85721

2Corresponding author: kmauz@u.arizona.edu

${ }^{3}$ Deceased, 1914-2009. 
west side of the Canelo Hills within the Coronado National Forest. With the exception of a shaded area under the canopy of an oak, $M$. mollis occupies the area of the pond floor that is seasonally exposed and inundated, and it extends to a narrow capillary fringe above the high-water mark. Minor grazing and watering activity by cattle occurs around the pond. The neighboring valley is a broad grassland punctuated by springs and typically dry arroyos with few trees, on the U.S. side of the international border with the state of Sonora, Mexico.

More than half of the annual rainfall in the semidesert grassland occurs in the 5 months (June-October) influenced by the North American Monsoon and residual tropical storms; on average, $271 \mathrm{~mm}$ falls near the study area during this season. Less than one-third of the annual total falls in the 4 winter months (December-March)-129 $\mathrm{mm}$ on average near the study area-and typically little, if any, rain falls in the late spring and late fall ("Monthly Rainfall Normals, 1971-2000, across Southeast Arizona"; available from: http: //www.wrh.noaa .gov/twc/climate/seaz_rainfall_normals.php [Canelo $1 \mathrm{NW}$ station]; accessed Oct. 2006). The 2 rainfall years surrounding the study period differed markedly from each other. In summer 2005, the area received $294 \mathrm{~mm}$ of precipitation, followed by $54 \mathrm{~mm}$ of rainfall in winter 2005/2006. In contrast, $457 \mathrm{~mm}$ of rain fell in summer 2006, followed by $144 \mathrm{~mm}$ of rain in winter 2006/2007. Temperatures during the study period ranged from the monthly average high of $33{ }^{\circ} \mathrm{C}$ (June 2006) to the monthly average low of $-5.3^{\circ} \mathrm{C}$ (January 2007). Monthly average low temperatures in the area are typically below freezing for 3 months of the year (December-February). Temperature conditions were comparable between summer 2005 and summer 2006. In winter seasons, the 4-month average high temperature was $1.8^{\circ} \mathrm{C}$ warmer and the 4-month average low temperature was $1.5^{\circ} \mathrm{C}$ warmer in $2005 / 2006$ than in 2006/2007 ("Southeast Arizona Monthly Cooperative Data"; available from: http://www.wrh.noaa. gov/twc/climate/coop/data.php [Canelo and Patagonia stations, Santa Cruz County]; last accessed Oct. 2007).

\section{METHODS}

Fieldwork with the Marsilea was conducted between April 2006 and May 2007. On one date in each year (10 May 2006 and 9 May 2007), clusters of terrestrial plants and their rhizomes were collected from the exposed floor of the southeast side of the pond. In 2006, plants were collected in a paper bag and allowed to desiccate prior to examination. By 2007, we were aware of the weevil's emergence behavior, so the paper bag was placed within a zip-seal plastic bag in order to trap emerging insects.

Sporocarps were removed from the collected plants after 6 weeks (when live insect emergence had long since ceased), and the dry plants were weighed and stored. Sporocarps were denuded using dissecting tools under a 10X binocular scope, sorted into mature (biconvex) and undeveloped (flat or essentially flat) fractions, and inspected for oviposition and exit holes. Counts were made of each of these fractions to document Marsilea fecundity and rates of parasitism among the samples.

Length, including the raphe (the attached portion of the pedicel), and width of 80 mature sporocarps from each year were measured with a digital caliper (Mitutoyo Corp., model NTD13-6C). Summary statistics (mean and 95\% confidence interval around the mean) and one-way analysis of variance (ANOVA) comparing sporocarp dimensions between years were computed using JMP statistical software (SAS Institute, Inc. 2000).

In the 2006 sample, $20 \%$ of mature sporocarps with oviposition holes but without exit holes were selected for destructive examination of contents. These selections were made to document the wasp in collections from 2006, when the live insects were not seen. In the 2007 sample, locations of oviposition and completed exit holes were recorded for those sporocarps having both. Based on the conventional orientation of sporocarps in illustration (e.g., Puri and Garg 1953: 198; Johnson 1986: 19), the margin where the pedicel attaches is the posterior and is the perspective from which right and left sides are recognized. In this study, the end opposite the raphe is the anterior margin, and the "top" and "bottom" margins are referred to as superior and inferior, respectively.

An initial collection of M. mollis (26 April 2006) in which a live weevil larva was discovered in a sporocarp led to the subsequent collection (10 May 2006) in which adult weevils were found with the plants. In the Marsilea collection of 2007, insects were captured individually in cellulose capsules as they emerged 
into the outer collection bag, and they were later mounted for examination. Mounted specimens from both years have been deposited with the Entomology collection at University of Arizona (UAIC; Tucson). In addition, 2 specimens from the original collection of Notiodes sporocarpicus are in the collection of Charles W. O’Brien (CWOB; Green Valley, Arizona), and 6 Lyrcus maculatus were sent to the Canadian National Collection of Insects (CNC; Ottawa, Ontario), where their identities were verified. Remaining sporocarp samples reside with the first author (KM). Plant voucher specimens have been deposited at the University of Arizona Herbarium (ARIZ; Tucson).

\section{RESULTS}

\section{Sporocarp Production by Marsilea mollis}

Reproductive phenology of Marsilea mollis was documented by observation at intervals in the field. Sporocarps were not observed on 17 February 2007 (KM). Young sporocarps were seen on 26 March 2007 (JR), and a heavy crop of green sporocarps was present on 23 April 2007 (KM). In both 2006 and 2007, substantially mature sporocarps were predominant in May: $78 \%$ were mature on day-of-year 130 in 2006 , and $84 \%$ were mature on day-of-year 129 in 2007. Sporocarps were not found on terrestrial plants on 14 July 2006 (KM), a time when both terrestrial and aquatic phases of $M$. mollis were present at the study site.

Fecundity differed markedly between the 2 years. Marsilea mollis specimens yielded 790 (2006) and 1328 (2007) sporocarps for $14.2 \mathrm{~g}$ (2006) and $11.2 \mathrm{~g}$ (2007) dry weight of plants collected. Total yield, including undeveloped sporocarps, was 56 (2006) and 119 (2007) sporocarps per gram dry weight of plants. Mature sporocarps numbered 44 (2006) and 100 (2007) per gram dry weight of plants in these samples. Undeveloped sporocarps on the collection dates could have been immature or else abortive. Damage other than oviposition and exit holes (possibly a result of insect feeding) was observed on 52\% (2006) and 25\% (2007) of undeveloped sporocarps and may have been a factor in the failure of sporocarps in these fractions to grow.

Mature sporocarps $(n=160)$ from the study site averaged $3.33 \mathrm{~mm}(95 \%$ CI $3.29-3.37 \mathrm{~mm})$ long and $2.53 \mathrm{~mm}(95 \%$ CI $2.51-2.56 \mathrm{~mm})$ wide. Lengths ranged from 2.52 to $3.97 \mathrm{~mm}$ and were, on average, $0.14 \mathrm{~mm}$ greater in 2006 than in $2007\left(F_{1,158}=13.8, P=0.0003\right)$. Widths ranged from 2.06 to $2.97 \mathrm{~mm}$ and were, on average, $0.09 \mathrm{~mm}$ greater in 2006 than in 2007 $\left(F_{1,158}=12.6, P=0.0005\right)$. Although these differences between years were statistically significant, the ratio between length and width did not differ between years $\left(F_{1,158}=0.66\right.$, $P=0.42$ ).

Parasitic Relationships Involving Marsilea mollis Sporocarps

Use of the Marsilea mollis sporocarp as a brood chamber by the weevil Notiodes sporocarpicus was documented by counting sporocarps with oviposition holes. According to Board and Burke (1971), an oviposition hole is chewed by the female weevil through the wall of the sporocarp and then sealed after an egg has been placed inside. Oviposition holes in our samples were about $0.1 \mathrm{~mm}$ wide and often did contain a plug of differently colored material (Fig. 1). Oviposition holes were observed on $19 \%(2006)$ and $28 \%$ (2007) of mature sporocarps and on 24\% (both 2006 and 2007) of undeveloped sporocarps in the samples.

Exit holes are made by adults of both the weevil and its wasp parasitoid. Those definitively made by Notiodes sporocarpicus (i.e., those where the weevil was still inside the sporocarp or where the adult emerged into a sealed capsule) were uniformly about $1.0 \mathrm{~mm}$ across. To emerge, the weevil first chews a circle through the inner wall of the sporocarp, leaving a thin layer of epidermis intact. Then it finally chews through this layer to complete the emergence (Fig. 1). Exit holes definitively made by Lyrcus maculatus were smaller $(0.4-0.5 \mathrm{~mm})$ but variable in size. In total, incipient and completed exit holes were observed on 7\% (2006) and 14\% (2007) of mature sporocarps in the samples analyzed.

Locations of oviposition and exit holes varied but seldom coincided with each other in the combined sample from 2006 and 2007: of 67 sporocarps with exit holes that had been initiated but not completed, only 2 had an oviposition hole on the site of the incipient exit hole; of 134 sporocarps with completed exit holes, only 1 exit hole appeared to have obliterated the oviposition hole. In the 2007 sample, oviposition holes were observed in all quadrants and margins of the sporocarps (Fig. 2a), with more sited in the inferior half $(48 \%)$ and 


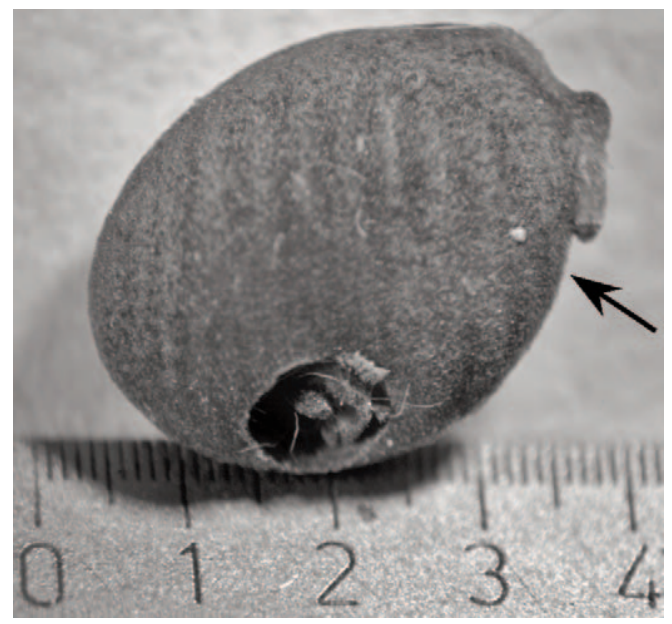

Fig. 1. Sporocarp of Marsilea mollis (left side) exhibiting signs of parasitism (Mauz \& Reeder \#2006-S014; UAIC). Arrow indicates an oviposition hole plugged with whitish material. The exit hole in the anterior-inferior position was made by the weevil Notiodes sporocarpicus. Its snout and forelegs are visible in the opening. Numbered scale divisions are in millimeters.

anterior (56\%) than in the superior half (36\%) and posterior $(30 \%)$. Exit holes occurred predominantly in the inferior half $(82 \%)$ and anterior $(60 \%)$, and uncommonly in the superior half $(3 \%)$ and posterior $(21 \%)$ regions of the sporocarps. Nearly half of all exit holes observed in this sample were in the anterior-inferior quadrant (Fig. 2b).

To document wasp parasitoid occurrence in 2006, the year when emerging adult insects were not collected, a $20 \%$ sample $(n=19)$ of mature sporocarps that had oviposition holes but not exit holes was subjected to destructive analysis: the sporangial contents of 15 sporocarps were intact, 2 each contained 1 Notiodes sporocarpicus larva, and 2 each contained a single adult Lyrcus maculatus. In the 2007 collection, from which emerging insects were systematically captured, 18 weevils emerged over 34 days, and 37 wasps emerged over 26 days. Additionally, among 111 sporocarps with completed exit holes in the sample from 2007, 13 still each contained a weevil, and 1 still contained a wasp.

\section{DISCUSSION}

On the basis of fertile herbarium specimens, Johnson (1986) indicated that sporocarps in
Arizona populations of Marsilea mollis are produced, or are at least present on the plants, from May to October. We suggest that sporocarp production in this southern Arizona population of M. mollis is limited to the springtime months (March-May), although sporocarps of the same year may persist on some plants beyond this time frame.

Sporocarp production in spring 2007 was more than twice that of spring 2006. Although a period of 2 years is unlikely to capture the range of variability in the plant's fecundity, these results qualitatively reflect differences in weather conditions-notably the much-drierthan-average and warmer winter of $2005 / 2006$, and the wetter-than-average and cooler winter of 2006/2007 (see Study Area, above). It is possible that in 2006-2007 these conditions promoted greater effective moisture in the soil across the Marsilea zone (the pond floor between lowstand and highstand) during the period when sporocarps were being produced. In contrast to sporocarp production, rates of parasitism as evidenced by oviposition holes were comparable between the 2 years.

Use of the Marsilea mollis sporocarp as a brood chamber by Notiodes sporocarpicus appears to be obligatory. In contrast, the tiny wasp Lyrcus maculatus is a common and widespread parasitoid of a wide range of insect hosts that are, in turn, associated with a variety of plant species (Gibson et al. 2006). Lyrcus maculatus is one parasitoid of N. celatus in the only other published Notiodes-Marsilea system, in Texas (Board and Burke 1971); however its specificity to the analogous system in this study is unknown, as is its possible association with other hosts in the study area.

Oviposition holes were observed on both undeveloped and mature sporocarps collected at one time in the growing season, and both larval and adult weevils were found in mature sporocarps in this sample. The presence of different stages of weevil development indicates multiple episodes of oviposition in the Marsilea mollis population. We cannot say, however, whether this represents different cohorts of eggs that were all deposited in young sporocarps; or whether egg deposition occurs at different times indiscriminate of sporocarp development (and whether sporocarp maturity at the time of oviposition bears upon egg or larval fate); or even whether the young sporocarps in the sample had, in fact, been injured by 


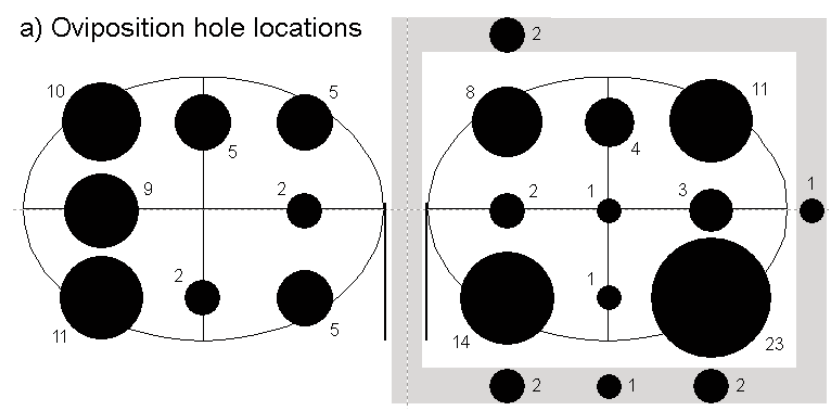

(left side) $\quad$ (right side)

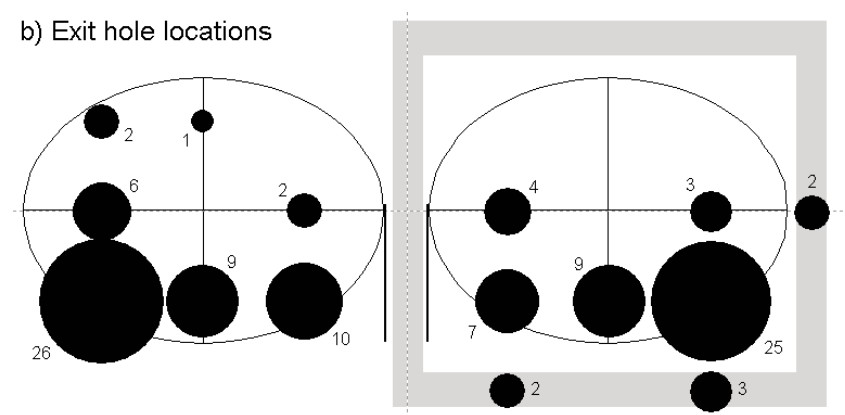

Fig. 2. Locations and counts of (a) oviposition $(n=126)$ and $(b)$ completed exit $(n=111)$ holes for 111 mature sporocarps collected in 2007. The pedicel is at the center of each schematic sporocarp diagram; the gray box represents the perimeter of the sporocarp.

oviposition and thus were halted in their development. Although they did not comment on sporocarp development at the time of oviposition, Board and Burke (1971) noted several overlapping generations of Notiodes celatusin which the developmental cycle lasted 3-4 weeks-occurring during the reproductive season of M. vestita, that in their locality in southern Texas begins at least as early as June and lasts into September. The sporocarp production season of $M$. mollis is relatively abbreviated, but it is possible that, if its developmental cycle is similar to that of $N$. celatus, 2-3 generations of $N$. sporocarpicus could emerge within this time frame.

Sporocarp size in Marsilea mollis appears to restrict brood size to one individual of Notiodes sporocarpicus per sporocarp. Although a fraction of sporocarps showing evidence of parasitism had more than one oviposition hole, none in which an adult insect (weevil or wasp) was found contained more than one individual. In contrast, Board and Burke (1971) reported up to $5 \mathrm{~N}$. celatus larvae in a single sporocarp of $M$. vestita. While the length of adult $N$. celatus (range 1.90-3.00 mm, $n=$ 187; C.W. O'Brien unpublished data) is about 1.2 times that of $N$. sporocarpicus, the sporocarps of $M$. vestita are, on average, up to 2 times longer (range 3.6-7.6 mm long) and wider (range 3.1-6.5 $\mathrm{mm}$ wide) than the sporocarps of M. mollis (Johnson 1986, Johnson 1993).

Our observations of oviposition and exit holes contradict the suggestion by Board and Burke (1971) that a new adult Notiodes celatus weevil emerges at the site of the oviposition hole in the sporocarp of Marsilea vestita. On the contrary, it was exceedingly uncommon for the 2 hole locations to coincide in the sample of $M$. mollis sporocarps analyzed. Furthermore, there is a clear bias toward emergence in the inferior half of the sporocarp. This pattern certainly reflects the anatomy of the sporocarp: the lower two-thirds of the sporocarp cavity is occupied by the edible spores and, once those have been consumed, becomes the pupation chamber for the weevil. The close correspondence in size between sporocarps of M. mollis and adults of N. sporocarpicus leaves little or no room for the rigid adult weevil to 
turn or rotate, as adults of $N$. celatus might do within the larger sporocarp cavity in $M$. vestita. The adults of $N$. sporocarpicus must be oriented essentially horizontally within the $M$. mollis sporocarp and so must initiate their exit hole at the point in front of their snout.

\section{CONCLUSION}

Populations of Marsilea mollis are scattered in the northern part of the species' range where it enters the southwestern United States. In the study area, the plant is known at only a few of the many earthen stock ponds in the San Rafael Valley and neighboring hills. Though unstudied, seasonal hydrology and pond-basin morphology are likely important factors influencing establishment or absence of a Marsilea population. In an established population, soil moisture during the winter and spring may further influence sporocarp fecundity. This fern is the reproductive host and a food source for the weevil Notiodes sporocarpicus, and this weevil is so far known to occur in only 2 populations of $M$. mollis in the study area. The fern occurs widely in Mexico, however, and N. sporocarpicus populations may eventually be found there. This simple system reflects a long-term ecological association between weevil and fern, and the special habitat that supports this association should be recognized by managers of land and water resources where these species are found.

\section{ACKNOWLEDGMENTS}

We thank Carl Olson (Department of Entomology, University of Arizona) for assistance with curation of our insect specimens and for facilitating identification of the weevil through Charles W. O'Brien, who described the species and provided useful correspondence. Gary A. P. Gibson (Canadian National Collection of
Insects, Ottawa) identified the wasp parasitoid in our samples and provided helpful references. George Yatskievych (Missouri Botanical Garden, St. Louis) provoked our original investigation of the Marsilea. Philip Rosen (University of Arizona) and Paul Myrow (Colorado College, Colorado Springs) each permitted use of laboratory resources. I recall with gratitude that John Reeder and I shared the discovery of Notiodes sporocarpicus and observe with regret that my first new species was also his last.

\section{Literature Cited}

BOARD, V.V., AND H.R. BURKE. 1971. Observations on the life history and habits of Endalus celatus Burke (Coleoptera: Curculionidae). Coleopterists Bulletin 25:63-65. Available from: http://www.jstor.org/stable/3999563

Gibson, G.A.P., M.W. Gates, and G.D. Buntin. 2006. Parasitoids (Hymenoptera: Chalcidoidea) of the cabbage seedpod weevil (Coleoptera: Curculionidae) in Georgia, USA. Journal of Hymenoptera Research 15:187-207.

Johnson, D.M. 1986. Systematics of the New World species of Marsilea (Marsileaceae). Systematic Botany Monographs 11, American Society of Plant Taxonomists, Ann Arbor, MI.

1993. Marsileaceae Mirbel-water-clover family. Pages 331-335 in Flora of North America Editorial Committee, editors, Flora of North America, Volume 2: Pteridophytes and Gymnosperms. Oxford University Press, New York and Oxford.

LOYAL, D.S., AND K. KUMAR. 1977. Utilization of Marsilea sporocarps as sham seeds by a weevil. American Fern Journal 67:95. Available from: http://www.jstor .org/stable/1546772

Puri, V., AND M.L. Garg. 1953. A contribution to the anatomy of the sporocarp of Marsilea minuta with a discussion of the nature of the sporocarp in the Marsileaceae. Phytomorphology 3:190-209.

SAS Institute, INC. 2000. JMP IN statistical software. Version 4.0.2. Duxbury Press, Pacific Grove, CA.

Received 11 November 2008 Accepted 1 July 2009 